\title{
CURRENT LEADS FOR THE WENDELSTEIN 7-X SUPERCONDUCTING MAGNET SYSTEM
}

\author{
T. Rummel ${ }^{1}$, F. Schauer ${ }^{1}$, T. Moennich ${ }^{1}$, K.-P. Buscher ${ }^{1}$, W. H. Fietz ${ }^{2}$, R. Heller ${ }^{2}$ \\ ${ }^{1}$ Max-Planck-Institute for Plasma Physics, Euratom Association, 17491 Greifswald, Germany \\ ${ }^{2}$ Karlsruhe Institute of Technology, 76021 Karlsruhe, Germany \\ Corresponding author e-mail: thomas.rummel@ipp.mpg.de
}

\begin{abstract}
The stellarator fusion experiment Wendelstein 7-X (W7-X) is presently under assembly at the Greifswald branch of the Max Planck Institute for Plasma Physics (IPP), Germany. The W7-X superconducting magnet system basically consists of 50 non planar and 20 planar coils including the interconnecting bus bars, and the support structure. The seven electrical circuits with ten coils each in series, are supplied by 14 current leads (CL) operating between the cryogenic and ambient temperature environments. A special feature of these feed throughs is their upside-down orientation to save space in the vicinity of the machine. Basic electrical CL requirements are maximal steady state currents of $18.2 \mathrm{kA}$ and voltage strengths of $13 \mathrm{kV}$ to ground. A W7-X current lead consists of a copper conductor which also acts as a heat exchanger at the warm end side, in its continuation of a high temperature superconductor (HTS) part, and at the cold end side of a copper bar with integrated $\mathrm{Nb}_{3} S n$ rods. All components are fully contained within a $C L$ vacuum chamber which is separated from the main W7-X cryostat vacuum. The high voltage electrical insulation is built up of a glass tape epoxy resin system. Mechanical support of the current leads is achieved by a warm and cold glass fiber reinforced plastic flange. There are three He cooling circuits: one for the bus bar and contact cooling, one for the cold end of the CL (both at about $5 \mathrm{~K}$ ), and one for the CL's heat exchanger (entrance temperature about $50 \mathrm{~K}$ ). After intensive tests of two prototypes the series production has been established and completed. The current leads were tested at room temperature (high voltage, helium leaks, instrumentation, etc.), and with electrical currents up to the maximum current at cryogenic temperatures. The paper gives an overview of the basic CL design requirements and layout as well as on the fabrication and acceptance tests. Further, a description of the assembly progress is given.
\end{abstract}

Keywords—current lead; Wendelstein 7-X; high temperature superconductor;

\section{INTRODUCTION}

The stellarator fusion experiment Wendelstein 7-X (W7-X) is presently under assembly at the Greifswald branch of the Max Planck Institute for Plasma Physics (IPP), Germany. W7-X has a plasma radius of 0.5 meter and an outer diameter of 16 meter. To allow steady state operation the magnet system is superconducting. It basically consists of 50 non planar and 20 planar coils including the interconnecting bus bars, and the support structure. The system is arranged in seven electrical circuits with ten coils each in series. Each circuit is powered by its own power supply. The transition from the room temperature bus bar system to the superconducting coils, operated at 4 Kelvin, will be handled via current leads. For the seven circuits 14 current leads (CL) operating between the cryogenic and ambient temperature environments, are necessary. Basic electrical CL requirements are maximal steady state currents of $18.2 \mathrm{kA}$ and voltage strengths of $13 \mathrm{kV}$ to ground.

In principle the aim of current leads is to provide a good electrical (low resistive) contact between the components inside and outside of the cryostat while keeping ohmic heat generation and thermal conduction as small as possible. This conflict requires careful optimization taking into account the intended operation scenarios. In the usual way of operation the magnets will be switched off during the night. With respect to a full year, the current leads would be in idle mode for about $90 \%$ of the time, and are therefore designed for low idle losses [1], [2].

In Wendelstein 7-X the situation has become different. Based on prediction about the allowed number of cycles for support elements of the magnet system, the design limit has been set to 1000 full load cycles of the magnet system. For that reason it was decided to design all systems to be suited for weekly instead of daily magnet operation cycles which consequently also changed the optimization base of the current leads. It is important to reduce also the load losses in order to save refrigerator reserves for high load cases which are provided in form of liquid helium. The latter is produced during idle or low load operation and can be used to boost the refrigerator power in case of need. In weekly magnet load cycles it could happen that not sufficient He could be produced overnight which possibly might necessitate to increase the LHe storage capacity and/or to add refrigeration power. Therefore it was decided to go for the much more expensive high temperature superconductor (HTS) current leads to be produced at the Karlsruhe Institute of Technology (KIT), Germany. An additional argument for this decision was the experience and available technology particularly for the HTS insert but also for the other CL components which could be adapted to the W7-X needs. Another core component is the He-cooled conductor (also "heat exchanger") between the room temperature level and the warm end of the HTS insert which was derived from the CERN LHC current lead conductor. 


\section{SPECIAL ReQUIREMENTS IN W7-X}

A particular requirement for the W7-X current leads is their upside-down-orientation which means that the warm end of the CL is at the bottom end the cold end at the top. To our knowledge, in all other facilities employing medium sized or large superconducting magnet systems like particle accelerators or fusion experiments current leads are used mainly with their cold ends at the bottom and in some cases in horizontal arrangement. The conventional orientation with the cold end at the bottom allows natural convection cooling with helium which is essential for all vapor cooled leads. There the inflowing heat at the bottom evaporates LHe and this vapor is used on its way upwards to cool the conductor (which usually has a large surface for sufficient heat transfer). In optimized leads the balance between heat generation as well as conduction in the conductor and evaporated He is such that at the warm end the temperature gradient is zero which means that no heat flows from the ambient into the cold environment. Other systems use forced flow helium which is necessary for horizontal leads anyway but offers also more flexibility to adjust for different load cases. However, current leads arranged in this conventional orientation have important disadvantages as well. They have to be installed on top of the cryostat or in a separate, mostly called "satellite" cryostat not too far from the machine. In case of W7-X the first solution would have required long power cables or bus bars to the power supplies located in the basement. Such power cables need much space, generate extra costs, and stray fields which lead to problems with the magnetic field quality. The variant to install the power supplies somewhere near the top of the machine was out of question due to lack of space. The other solution to install a satellite cryostat for the current leads would have generated even higher costs for the additional cryostat itself and the superconducting transfer line (at 4 Kelvin) between main and satellite cryostat. For the satellites even an extension of the building would have been required.

In conclusion it was rated to be favorable to install the current leads directly into the bottom side of the main cryostat and take the small development risk for upside-down orientation. Fig. 1 shows the locations of the current leads in W7-X.

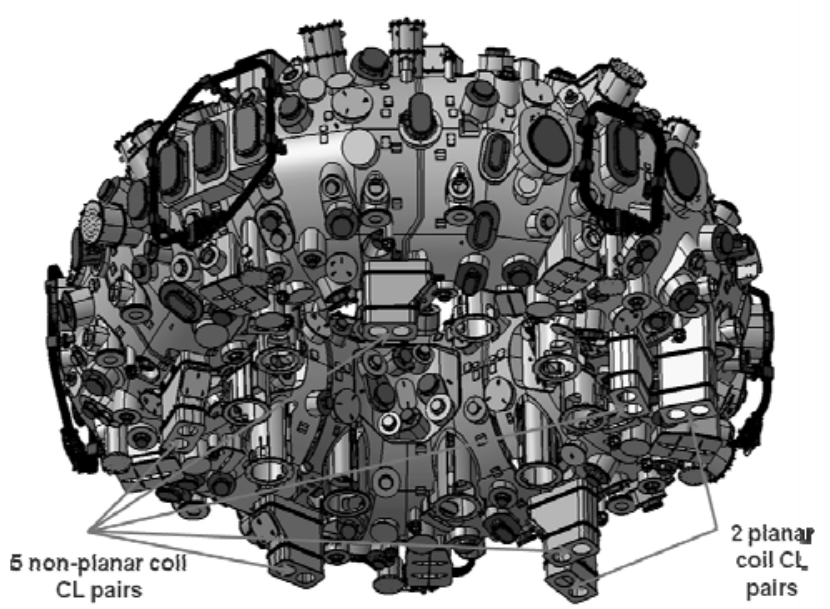

Fig. 1. Location of the current leads in W7-X (view from the bottom).

Other requirements for the current leads are based on the operation scenarios of the machine, i.e. for stable and low-loss operation at different currents up to the maximum design current of $18.2 \mathrm{kA}$ steady-state. The main operation current for the nonplanar coils is around $14 \mathrm{kA}$ corresponding to a stellarator axis-field of $2.5 \mathrm{~T}$. The planar coils will be operated at currents up to 12 kA only with the same type of current lead. During normal operation, only slow ramp rates are required with a maximum of $30 \mathrm{~A} / \mathrm{s}$. In case of a fast discharge of the magnet system, e.g. due to a quench in a superconducting component, the current will drop down from maximally $18.2 \mathrm{kA}$ to zero within 12 seconds. This ramp rate has consequently to be considered in the design of the leads.

All components of the CL are fully contained within a vacuum chamber which is separated from the main W7-X cryostat vacuum. The maximum leak rate should be lower than $1 \mathrm{E}-6 \mathrm{mbar} * 1 / \mathrm{s}$

All metallic components of the CL are at the same (high) potential which means that the outer surface needs to be completely covered with electrical insulation. Also the helium supply and discharge pipes have to be electrically separated from the rest of the grounded helium distribution system. During a fast coil discharge voltages of up to $6 \mathrm{kV}$ are expected in the worst case. Therefore, the current lead's insulation has to withstand test voltages of $13 \mathrm{kV}$ to ground.

Another requirement is that the current leads should be replaceable which requires detachable connections at all interfaces. The most critical one is the electrical contact to the cold bus bar system inside the cryostat where consequently only screwed 
connections were considered. Also the cold end vacuum cylinder and insulation had thus to be designed such that they could be opened and closed with reasonable effort.

\section{DESIGN OF THE W7-X CURRENT LEADS}

\section{A. Overview}

The design is based on new developed components as well as already used components. Examples for the latter ones are the cold contact which was derived from the joint between the CL and the previously tested W7-X coil prototype ("Demo coil"), the cooling principle of the contact, the warm contact, the vacuum chamber, the support system, the basic instrumentation, and the electrical insulation. The specification was finalized together with KIT which then also got the contract for the final design, fabrication, and test of the W7-X current leads. For the HTS insert the well proven KIT system was chosen, and for the conductor between the HTS warm end (at "intermediate" temperature) and the ambient temperature contact a variant of the corresponding LHC conductor was taken whose heat exchanging surface arrangement is suitable for upside-down helium cooling. Fig. 2 shows a current lead where the outer stainless steel tube was already insulated and the two G10 flanges glued on it.

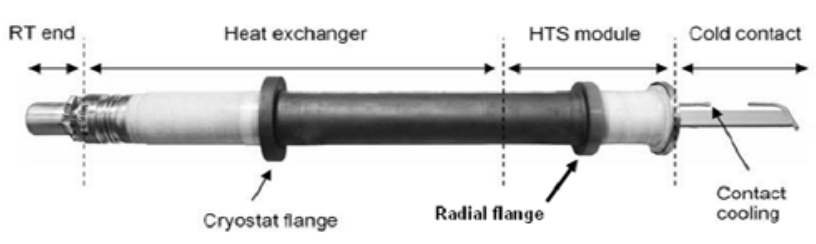

Fig. 2. 18.2 kA HTS current lead for W7-X developed at the Karlsruhe Institute of Technology using Bi-2223/AgAu tapes [3].

At both ends the connections to the room temperature power cables on the left and the superconducting bus bar on the right are shown. At the cold end an extra contact cooling has been applied to absorb a part of the heat load. It uses the helium from the return line of the coil casing cooling. A current lead is $2500 \mathrm{~mm}$ long, has a diameter of $310 \mathrm{~mm}$ and a weight of about $180 \mathrm{~kg}$.

In the following chapters the main components will be presented.

\section{B. HTS insert and heat exchanger}

HTS materials are very suitable to overcome the conflict between the requirements for low values of electrical resistance and heat conduction which is hard to deal with using conventional materials like metals or alloys. HTS are based on ceramics whose thermal as well as electrical conductivity is normally bad. But in the superconducting state its electrical conductivity rises up drastically while its thermal conductivity remains low.

The basic design developed for the ITER HTS current lead demonstrator was used as a base for the W7-X leads. They consist of a copper heat exchanger at the warm end side, a high temperature superconductor part and a copper bar with integrated $\mathrm{Nb}_{3} \mathrm{Sn}$ rods near the cold end side. The HTS material are Bi-2223/AgAu tapes with critical currents $>110 \mathrm{~A}$ (at $77 \mathrm{~K}$ and in self field) and sufficient mechanical strength. Soldered stacks from such material can be made by industry. As a result of the optimization, 60 stacks made of 6 tapes and grouped in 12 quintuplets are used [3]-[5]. Fig. 3 shows pictures of the HTS-element and the copper heat exchanger. The heat exchanger is made of one piece of copper, precisely machined at the KIT work shop. In Fig. 3 (bottom) the left hand side shows the warm end of the CL at room temperature whereas the right hand side is the $60 \mathrm{~K}$ region at the transition to the HTS module. A more detailed description can be found in [4].

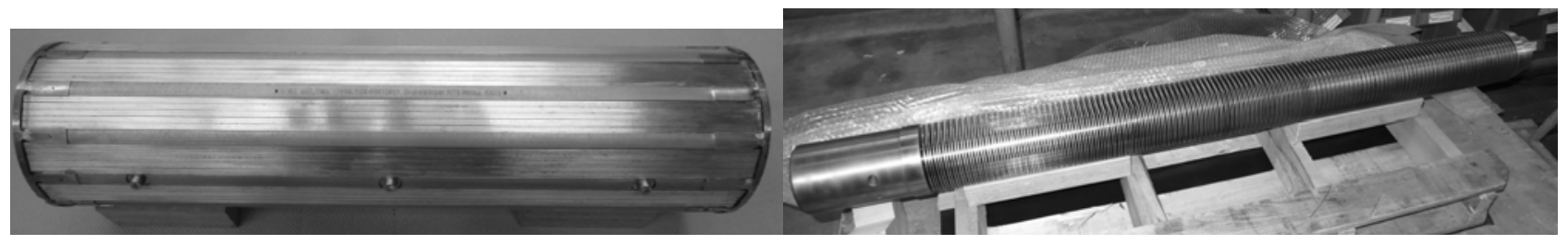

Fig. 3. HTS- module (top) and heat exchanger (bottom) designed and manufactured at KIT for the W7-X current lead.s [2]. 


\section{Cold contact}

The cold contact consists of a semicircular copper bar with integrated $\mathrm{Nb}_{3} \mathrm{Sn}$ rods (Fig. 4). The contact surface of $75 \times 300 \mathrm{~mm}$ is polished and gold plated. Three parallel cooling channels are integrated in the back side.

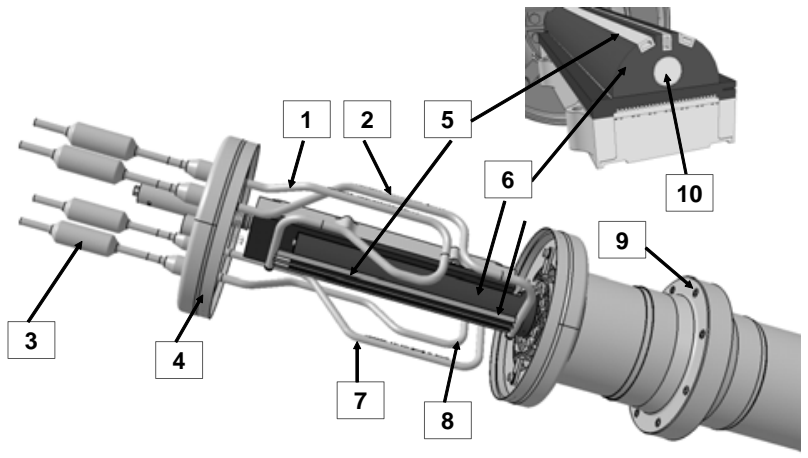

Fig. 4. Cooling loops at the cold end region of a CL (1: inlet cold contact cooling; 2: outlet of cold contact cooling; 3: potential breaks; 4: cold end top plate; 5: three parallel cooling channels in the cold contact; 6:cold contact; 7: inlet of the heat exchanger cooling at 50 K; 8: outlet of the bus bar cooling; 9: GRP flange; $10: \mathrm{Nb}_{3} \mathrm{Sn}$ insert).

\section{Cooling circuits}

There are three different cooling circuits in the CLs (Fig. 4). The first one is a $50 \mathrm{~K}$ helium circuit which enters the heat exchanger at its cold side (at the connection to the HTS) and leaves it at room temperature at the warm end contact of the CL (Fig. 5). The second cooling circuit delivers helium at about $5 \mathrm{~K}$ from the bus bar into the attached cold contact side (Fig. 4, item 8). The third circuit supplies helium at about $5 \mathrm{~K}$ to the other side of the cold contact at the cold end of the CL (Fig. 4, item 1 and 2). All helium inlets are located at the CL cold end plate (Fig. 4, item 4); the electrical separation is made by voltage breaks in each cooling line (Fig. 4, item 3). The two He return lines are located also at the cold end plate.

\section{E. Electrical insulation}

The electrical insulation is in accordance with the general insulation concept of W7-X. Therefore it has to withstand voltages of up to $13 \mathrm{kV}$ also under partial vacuum (Paschen) conditions and follows the same principle as other components in the W7-X cryostat. That means it consists of several layers of epoxy resin impregnated glass tapes or mats. Flat areas like the cold end plate were built up on underlying GRP plates. Critical regions like corners or gaps between GRP plates at the cold end plate were reinforced by Kapton tape. The minimum thickness of the final insulation is $4 \mathrm{~mm}$ for all components insulations. Due to the production sequence the insulation work had to be divided into several steps. First the vacuum cylinders of the heat exchanger, the HTS module, and the cold end, as well as the top plate of the cold end itself, were each insulated separately, leaving a few centimeters open at the respective ends. After connecting the cylinders with each other the remaining gaps were insulated. It has to be noted that this stepwise procedure had to be divided between several partners due to the different times and locations of the work. The insulation of the individual cylinders was performed by Marti Supratec either at the production site at KIT or in some cases at the Marti Supratec site (cold end cylinders) or by IPP (cold end plate). The insulation of the gaps was performed by KIT at its site. The gaps at the cold end cylinders are being insulated by IPP during the assembly directly at the W7-X machine. All the actions required tests and detailed descriptions of the procedures, and an intensive coordination and cooperation.

One other principle for W7-X construction is that all insulated parts have to be tested before their integration into the W7-X machine. Therefore components which could not be tested during the acceptance tests of the CLs because of their later installation have been tested separately after the assembly. The electrical insulation of major parts like cold end vacuum tubes and cold end plates including HV feed troughs was thermally cycled several times between RT and $77 \mathrm{~K}$ followed by HV tests also under Paschen conditions.

\section{F. Sensors}

The superconducting parts of the current leads are equipped with quench detection sensors. Voltage taps measure the voltage drop across the HTS module and the transition between CL and superconducting bus bar. Temperature measurements serve as input for the He mass flow and temperature control. These sensors are located at the warm and cold end sides of the HTS module, at the heat exchanger, and at the warm end of the CL. With decreasing current level the warm end temperature tends to decrease with the risk of freezing. In low or idle current mode two electrical heaters of $500 \mathrm{~W}$ each which are installed inside of the warm end copper contact keep it at room temperature level. Overheating is limited by helium mass flow increase through the heat exchanger. Aim is 
to hold the temperature of the warm end between 15 and 42 degrees Celsius. Fig. 5 shows the warm end side of a CL, equipped with sensor plugs, the helium return line plug and heater plugs.

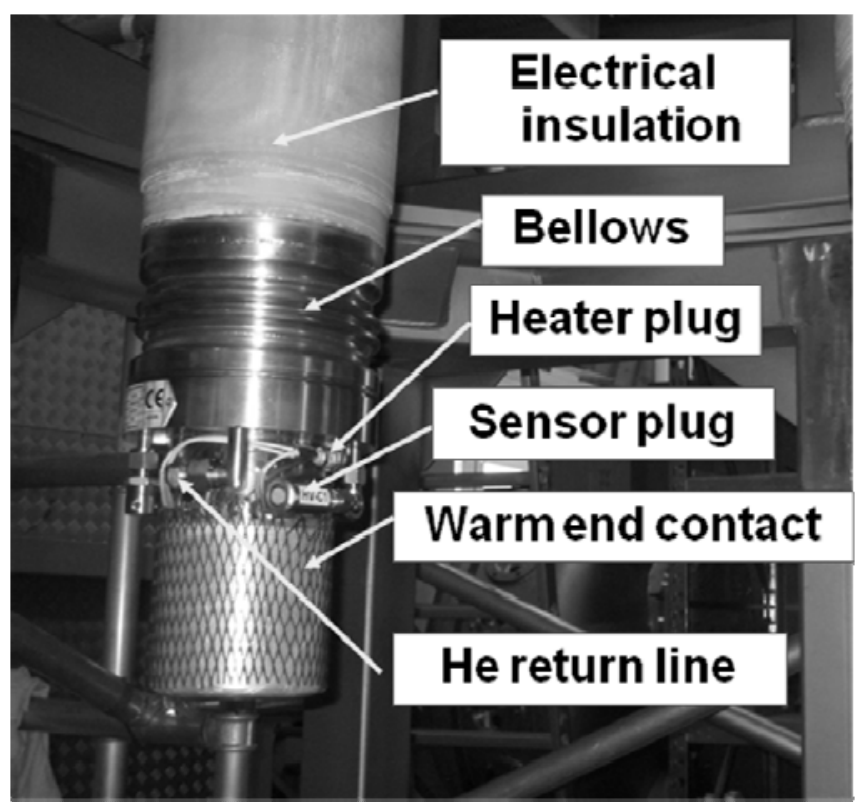

Fig. 5. Warm end side of a CL.

\section{G. Support flanges of the CLs}

The mechanical support of the current leads is achieved by two flanges, made of glass fiber reinforced composite. These flanges secure the mechanical fixation of the CLs to the magnet structure and outer vessel, respectively, and at the same time the electrical separation from these systems. The selection of GRP for the flanges was driven by the design of the electrical insulation which does not allow any gap in the outer surface of the CLs in order to achieve the Paschen tightness. Usage of GRP as flange material appeared to be best suited with respect to the quality of bonding to the CL insulation but also with respect to the thermal contraction during cool down and warm-up. The drawback of using a GRP flange is its limited mechanical strength (as compared to stainless steel), and therefore an intensive qualification program was launched. Both flanges have to operate under different conditions: the cold upper "radial" flange is connected to the magnet system operated at about 4 Kelvin. The lower "cryostat" flange is at room temperature and has also to secure the vacuum barrier of the cryostat against air. Leak tightness of the sealing as well as of the connection between CL insulation and flange were important issues of the qualification program. KIT was responsible for the development of the CL outer surface insulation and the bond between insulation and flange. The final solution was to create a small cavern between flange and insulation, and to inject a special epoxy resin as bonding material. IPP was responsible to secure the mechanical stiffness of the flanges themselves and of the connections to the CL insulation. Flange loads are mainly coming from vacuum forces, thermal contraction, from electromagnetic forces, and mechanical forces and moments from magnet system deformations and movements with respect to the cryostat.

In summary there are forces and moments in all directions of up to $9000 \mathrm{~N}$ and $775 \mathrm{Nm}$, respectively, according to extensive FE calculations. Prototype flanges, bonded on representative lengths of corresponding CL outer surface prototypes, were successfully tested at room temperature and $77 \mathrm{~K}$ to check the mechanical stability at up to $150 \%$ of the expected operation loads [7]. Fig. 6 shows a test arrangement for the mechanical tests of the GRP flanges. 


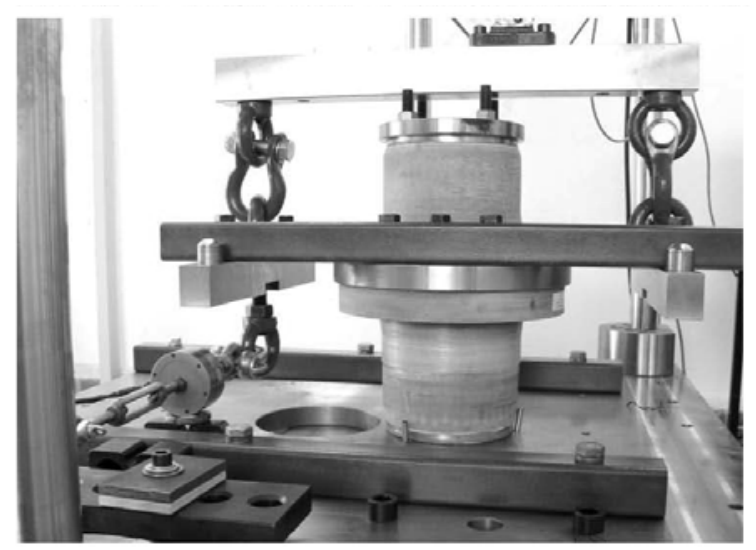

Fig. 6. Test arrangement for the mechanical test of a GRP flange.

\section{TESTS OF THE CURRENT LEADS}

General remarks:

After completion, both prototypes were tested in two test campaigns. All the series leads were also tested, but in a less extensive way. Main difference was that the prototypes were energized twice with a warming up and cooling down cycle in between. The aim was to demonstrate that such a cycle does not change the behavior of the CLs. In general a test campaign at KIT was divided into three mayor steps:

- Tests at room temperature

- Tests at cryogenic temperature in the TOSKA test facility

- $\quad$ Final check after warming up

\section{A. Tests at room temperature}

The tests were done at first with the cryostat still open and without connection of the CLs to the power supply or the data acquisition systems. The helium lines were connected and filled with helium at 6 bar minimum. In this condition a high voltage test of $13 \mathrm{kV}$ DC was performed. After that the sensor cables were installed and checked step by step by applying a current of $20 \mathrm{~A}$ to the CLs and evaluating the signals. Data transfer and proper storage was checked too. Next important step was a leak test of the individual helium and nitrogen lines within the CLs as well as within the whole test arrangement. An overall leak test was performed after closing the cryostat to confirm a leak rate $\leq 1 \mathrm{E}-5 \mathrm{mbar} * 1 / \mathrm{s}$ which was set as the acceptance level for start of the cool down process.

\section{B. Tests at cryogenic temperature}

\section{1) Cool down}

The test configuration was cooled down by the computer-controlled cryogenic system with an average rate of $10 \mathrm{~K}$ per hour. For the bus bar and mechanical structures of the test assemblies the maximal temperature differences between inlet and individual sensors as well as the outlets should not exceed $40 \mathrm{~K}$. The maximal temperature difference between inlet and individual temperature sensors of the HTS module should not exceed $65 \mathrm{~K}$. The temperature differences between individual components were maintained by adjusting their respective mass flow rates.

The data acquisition system took data points from the CLs with a sampling rate of $10 \mathrm{~Hz}$. The required vacuum level in the test cryostat which was an extension of the TOSKA cryostat, was below $10^{-4}$ mbar. Measurements of leak tightness, temperatures and flows, as well as function checks of the instrumentation were performed. Resistance and transition temperature measurements were performed at both the HTS and bus bars at a current of 20 A which was applied during the complete cool down process.

After the end of the cool down process, tests with different HTS helium inlet temperatures and He mass flows were performed to check the thermal stability and to determine the cold end heat load. This was compared to calculations, and the results were used to adjust the cryogenic operation parameters. The specification called for a temperature rise from the heat exchanger inlet to the 
warm side of the HTS of $10 \mathrm{~K}$. This temperature difference was set by adjusting the mass flow rate. The necessary mass flow was compared to the predicted one. Another aim of this measurement campaign was to separate the heat load of the current leads from the background losses of the test cryostat.

\section{2) Tests with electrical current}

The tests with electrical current needed more caution. Therefore a HV test, checks of the control and quench detection signals as well as of the safety (fast discharge) system at zero and at low current of $4 \mathrm{kA}$ was performed at the beginning of each day. The data acquisition sample rate of the quench detection signals was increased to $10 \mathrm{kHz}$. Then the current was increased with a ramp rate of $100 \mathrm{~A} / \mathrm{s}$ to the nominal current of $14 \mathrm{kA}$ and later to the maximal current of $18.2 \mathrm{kA}$. At both current levels the necessary helium mass flow for stable operation was measured and compared with the expectations. It was verified that the CLs run stable over six hours. An important failure in cryogenic applications is the so-called loss-of-flow-accident (LOFA). Such tests were performed by stopping the helium mass flow at a current of $18.2 \mathrm{kA}$ and measuring the time until the quench. The results define the criticality of the operation and the available time for counter measures in case of instabilities. The comparison between different CLs gave also indications about the production stability of the HTS. The tests of the safety margin and LOFA were followed by an operation with nominal current to verify that no damages were initiated by the tests.

\section{Final check-out after warming-up}

After warming-up of the test arrangement HV tests as well as helium leak tests were performed again. After uninstalling the current leads had to undergo another HV test at reduced air pressure (Paschentest) in an external vacuum chamber.

\section{Findings during the tests}

Table I gives an overview about the results of the cryogenic tests.

TABLE I. TEST RESULT OVERVIEW

\begin{tabular}{|c|c|c|c|}
\hline \multirow[b]{2}{*}{ Parameter } & \multirow{2}{*}{$\begin{array}{l}\text { Design / } \\
\text { Target } \\
\text { value }\end{array}$} & \multicolumn{2}{|c|}{ Test results } \\
\hline & & $\begin{array}{l}\text { Mean } \\
\text { value }\end{array}$ & $\begin{array}{c}\text { Min/Max } \\
\text { value }\end{array}$ \\
\hline $\begin{array}{l}\text { Contact resistances at HTS- } \\
\text { module (cold and warm } \\
\text { end) }\end{array}$ & $<25 \mathrm{n} \Omega$ & $16.8 \mathrm{n} \Omega$ & $15 / 21 \mathrm{n} \Omega$ \\
\hline \multicolumn{4}{|c|}{ Standby (0 kA) } \\
\hline $\begin{array}{l}\text { Nominal/Maximum helium } \\
\text { mass flow at } 50 \mathrm{~K} \text { inlet } \\
\text { temp. }\end{array}$ & $0.6 / 1.0 \mathrm{~g} / \mathrm{s}$ & $0.52 \mathrm{~g} / \mathrm{s}$ & $\begin{array}{c}0.47 / 0.53 \\
\mathrm{~g} / \mathrm{s}\end{array}$ \\
\hline $\begin{array}{l}\text { Nominal heat flow to cold } \\
\text { contact at } 0 \mathrm{kA}\end{array}$ & $3.8 \mathrm{~W}$ & $2.1 \mathrm{~W}$ & $2 / 2.5 \mathrm{~W}$ \\
\hline \multicolumn{4}{|c|}{ Nominal current (14 kA) } \\
\hline $\begin{array}{l}\text { Nominal/Maximum helium } \\
\text { mass flow at } 50 \mathrm{~K} \text { inlet } \\
\text { temp. }\end{array}$ & $1.0 / 1.4 \mathrm{~g} / \mathrm{s}$ & $1.04 \mathrm{~g} / \mathrm{s}$ & $\begin{array}{c}1.03 / 1.06 \\
\mathrm{~g} / \mathrm{s}\end{array}$ \\
\hline $\begin{array}{l}\text { Nominal heat flow to cold } \\
\text { contact at } 0 \mathrm{kA}\end{array}$ & $4.2 \mathrm{~W}$ & $3.5 \mathrm{~W}$ & $3.1 / 3.7 \mathrm{~W}$ \\
\hline \multicolumn{4}{|c|}{ Maximum current (18.2 kA) } \\
\hline $\begin{array}{l}\text { Nominal/Maximum helium } \\
\text { mass flow at } 50 \mathrm{~K} \text { inlet } \\
\text { temp. }\end{array}$ & $1.3 / 1.8 \mathrm{~g} / \mathrm{s}$ & $1.38 \mathrm{~g} / \mathrm{s}$ & $\begin{array}{c}1.35 / 1.39 \\
\mathrm{~g} / \mathrm{s}\end{array}$ \\
\hline $\begin{array}{l}\text { Nominal heat flow to cold } \\
\text { contact }\end{array}$ & $4.6 \mathrm{~W}$ & $4.5 \mathrm{~W}$ & $3.9 / 5.8 \mathrm{~W}$ \\
\hline $\begin{array}{l}\text { Current sharing } \\
\text { temperature Tcs_0 }\end{array}$ & $72 \mathrm{~K}$ & $81 \mathrm{~K}$ & $76 / 86 \mathrm{~K}$ \\
\hline $\begin{array}{l}\text { Time after LOFA until } \\
\text { quench }\end{array}$ & $720 \mathrm{~s}$ & $1021 \mathrm{~s}$ & $979 / 1069 \mathrm{~s}$ \\
\hline
\end{tabular}

All current leads could be operated stably at different currents. Also a test during the prototype test campaign with $20 \mathrm{kA}$, which was above the specified maximal current of $18.2 \mathrm{kA}$, was successful. The quality of the heat exchanger, the critical component concerning the upside-down operation, meets the expectations well and shows a high level of uniformity between the 16 CLs. The necessary mass flow rates are in average $20 \%$ lower than specified. The LOFA tests demonstrated that the HTS module will not 
quench for about 1000 seconds after a stop of helium mass flow. This gives a high safety margin for operation in W7-X. A detailed analysis of the test results can be found in [8].

\section{ASSEMBly of the CURRENT LeAdS InTO W7-X}

The current leads are being installed at an extension of the cryostat at the bottom side. The link to the main support structure of the magnets is achieved by a system of rods and rectangular profiles, as shown in Fig. 7.

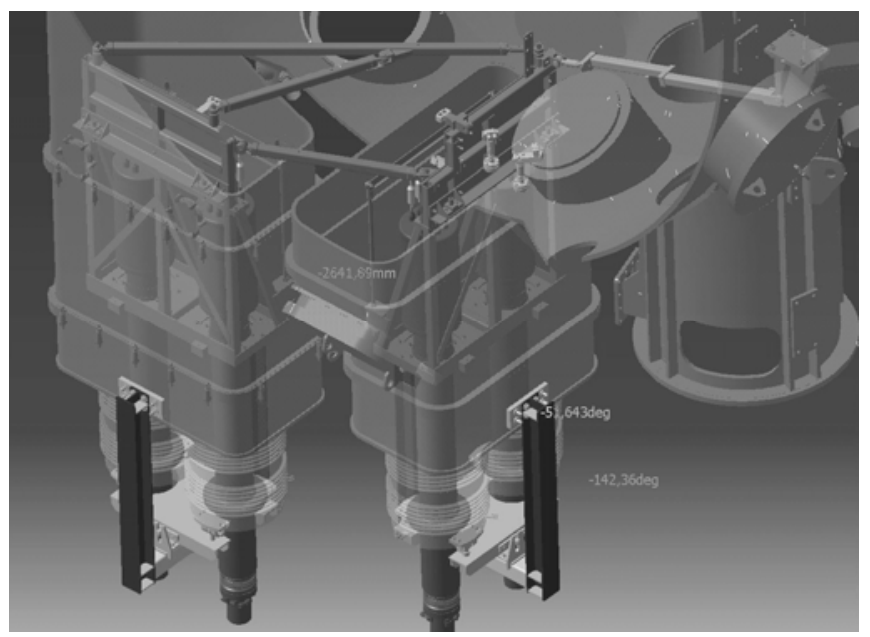

Fig. 7. Two pairs of current leads (blue) with fixing box (orange), lower supports (magenta, yellow), port extensions (grey), and rectangular support profiles (green).

The supports have to fulfill multiple requirements. Apart from carrying the dead weight, the structure has to allow also movements due to the magnet cool down and its deformations due to electromagnetic forces. These requirements implicate a relatively sophisticated support system.

The CL installation sequence and some special tooling were developed in close co-operation between IPP and ORNL, Oak Ridge, USA [9]. The assembly starts from top with the upper part of the fixing box (parts in orange in Fig. 7). Then the CLs are lifted from the bottom close to their final position. This is achieved in multiple steps by a special ramp:

- Mount temporary upper fixing box supports

- Mount and adjust upper fixing box

- Form and clamp conductors and He lines to upper fixing box

- Mount CL joints

- Mount and align lower fixing box

- Raise current leads and hold in position with Ramp 2

- Adjust and fix cold end plate by welding

- Adjust and make all final CL bus connections

- Adjust and weld all Helium lines

- Connect the quench detection wires at the cold end

- Slide the cold end vacuum cylinder over the cold end, weld it, perform leak tests, and apply the electrical insulation followed by a local Paschen test

- Install permanent stainless steel counterparts to the CL flanges

- Adjust and weld outer vessel port extensions with thermal insulation step by step to Outer Vessel (Fig. 8)

- Adjust lower support (Fig. 7) to transfer CL weight

- Connect the warm end connector plug and room temperature bus bar cables (Fig. 8)

- Connect the sensor cables to the plugs at the warm end side 


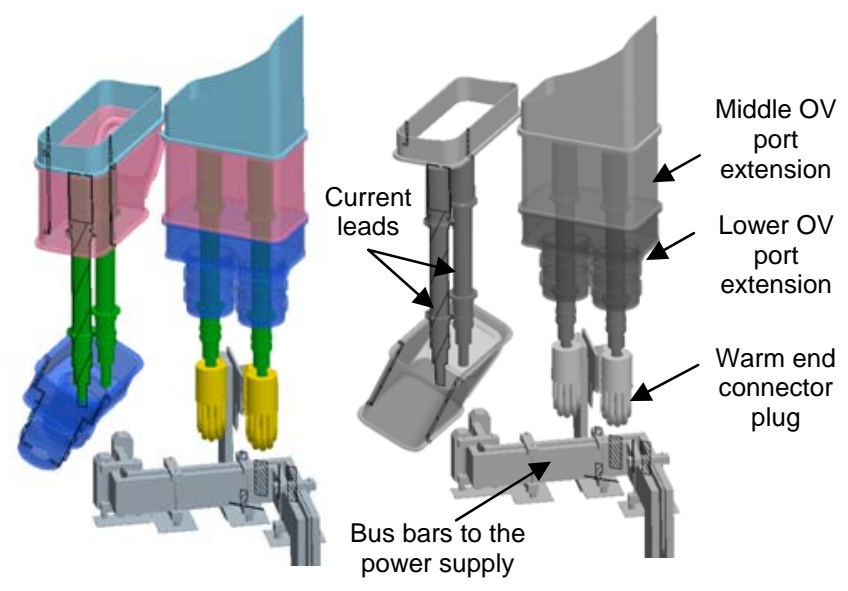

Fig. 8. Assembly sequence of the outer vessel (OV) parts.

One important item is the electrical connection of the CLs to the superconducting bus bar system. The components at the interface are the following (Fig. 9): at the CL side the interface is a flat surface, made of high conductive copper, and coated with a layer of a few microns of gold. The counterpart at the bus bar side is also a gold plated copper plate which has at its back side grooves where the superconducting strand bundles are soldered. This assembly is integrated in a helium tight stainless steel can, called joint box. The function of the joint box is to give the necessary stability for the clamps which press the two gold plated surfaces, with an indium foil in between, together with a pressure of $10 \mathrm{MPa}$.

During the tests in TOSKA two CLs were connected by a piece of conductor with joint boxes at both ends forming an electrical circuit. During several test campaigns of the acceptance tests unexpected high electrical resistances of up to $200 \mathrm{nOhm}$ across the contact were observed. As the joint boxes and clamping device were planned to be installed in W7-X also, this phenomenon was investigated with special attention.

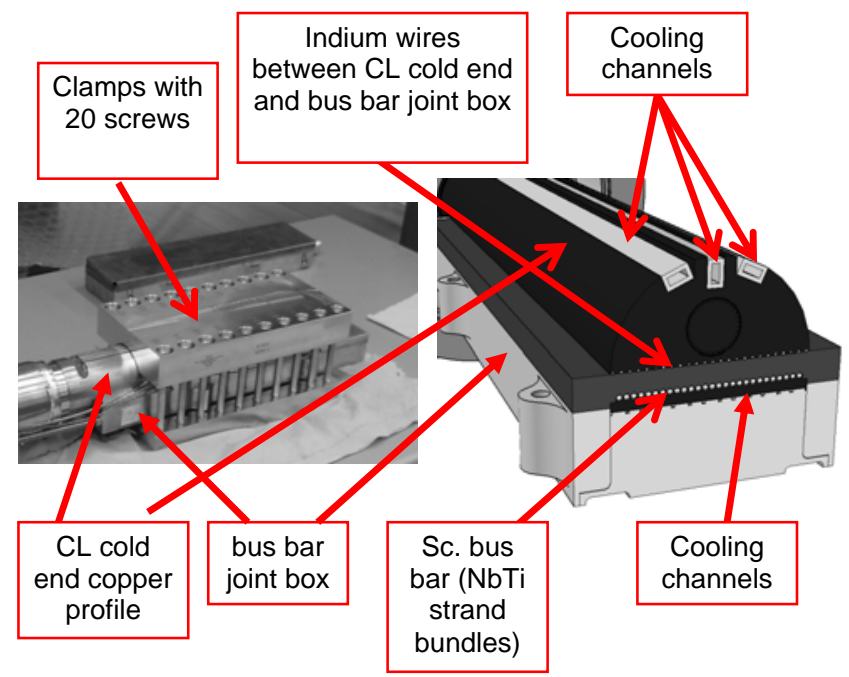

Fig. 9. Electrical connection between CL and bus bar.

Several attempts were made to influence the resistance. The contact pressure was increased, the flatness of the joint box surface was improved, the thickness of the indium foil was increased, the design of the joint box was improved for better pressure transfer from the clamp to the contact surface, the soldering of the strands into the copper plate was modified, and the solder material was checked for imperfections and degradation of properties. All these actions gave no clear indication of the source and location of the problem. Calculations and thermo-mechanical simulations which were performed in parallel gave hints but no clear explanation. However, it could be shown that the CL was not the origin of the problem. In order to develop a stable solution for the joint box and CL connection for W7-X, special mock-ups were produced and test programs at CRPP (Switzerland) and SINTEZ (Russia) were 
initiated. The aim of the tests was not anymore to find the explanation of the phenomenon appearing during the CL cold tests but was to develop a robust and easily applicable solution for W7-X. After a series of investigations the following decision was taken: All the improvements of the joint box and the soldering procedure are used. As major change the Indium foil is replaced by indium wires of $1.0 \mathrm{~mm}$ thickness. Such a system is usually applied by CRPP for cold contacts. All tests at $4 \mathrm{~K}$, performed at CRPP and SINTEZ, clearly demonstrated the proper behavior of the contact with a resistance of less than one n $\Omega$. Wires are squeezed more than a foil between the surfaces and give a very strong contact. As a drawback of this solution one has to accept that the two surfaces can only be separated with higher effort than the surfaces with indium foil in between. The squeezed indium wires in such a case have to be heated up until they start to melt. After separation the surfaces have to be polished extensively for re-use and newly gold plated. But this drawback is acceptable for these connections which need to be opened and closed again only in case of a failure.

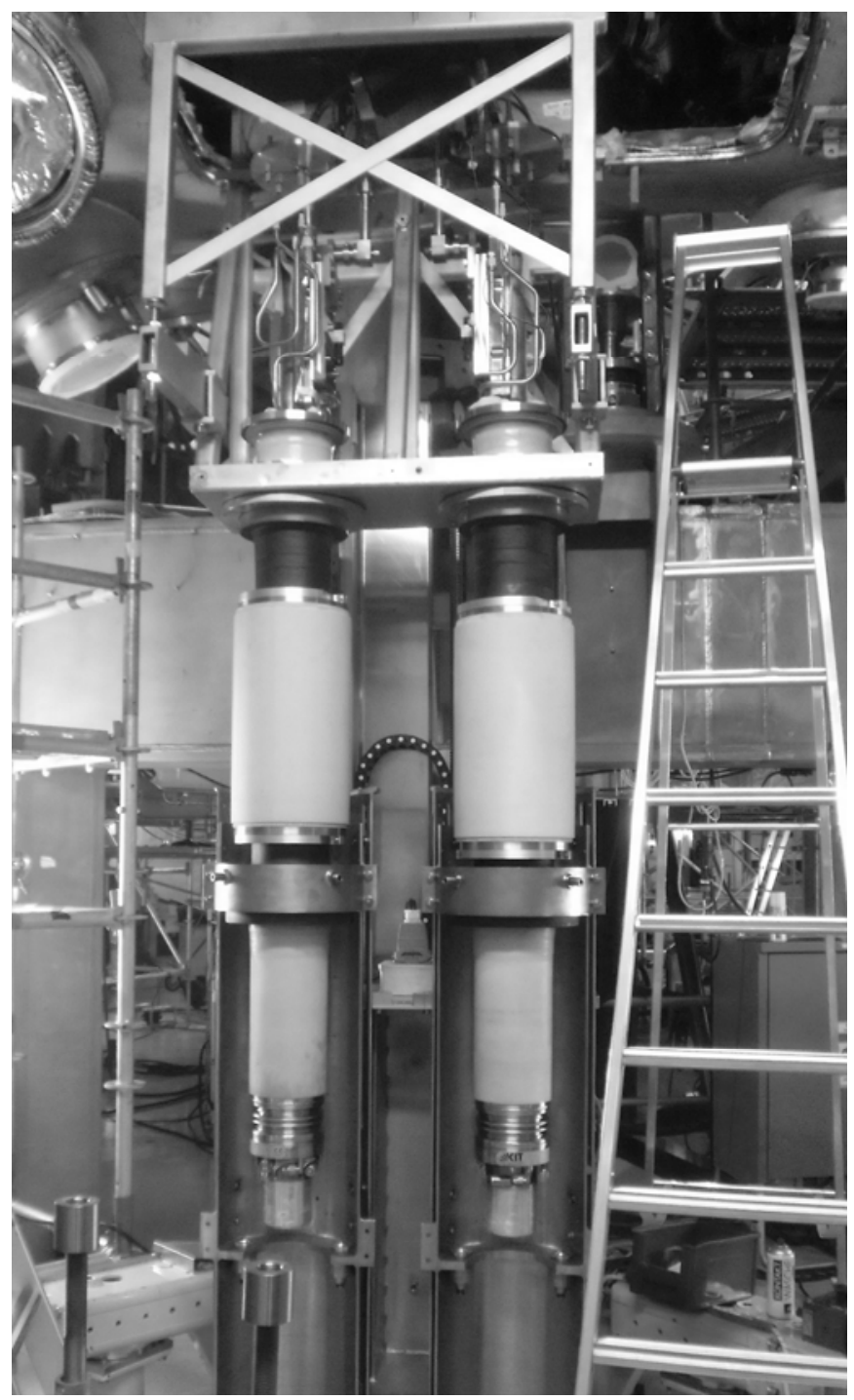

Fig. 10. A pair of current leads during installation in W7-X.

\section{SUMMARY AND OUTLOOK}

Fourteen current leads are necessary for the W7-X superconducting magnet system. All current leads and two prototypes which will act as spares have been produced and successfully tested under the operation conditions between 2006 and 2013 . The installation into W7-X has been started in 2012 and will be finished in spring 2014. Fig. 10 shows a current lead pair during the installation. 


\section{ACKNOWLEDGMENT}

The authors would like to thank all the involved colleagues at KIT and IPP for their work and co-operation. The authors thanks also the companies Marti Supratech AG, Wallisellen, Switzerland, for supplying test pieces of the flange assembly, Institut fuer Luft- und Kaeltetechnik GmbH (ILK), Dresden Germany, for thermal cycling of the test pieces, IMA Materialforschung und Anwendungstechnik GmbH, Dresden, Germany for the execution of modeling and thermo-mechanical tests of the flanges, as well as CRPP, Lausanne, Switzerland, and SINTEZ, St. Petersburg, Russia, for performing the tests of the joint boxes.

\section{REFERENCES}

[1] F. Schauer, H. Bau, Y. Boshko, R. Brockmann, M. Nagel, M. Pietsch, S. Raatz, "Cryotechnology for Wendelstein 7-X", Fusion Engineering and Design 6668 (2003), pp. 1045-1048.

[2] A. V. Gavrilin, J. R. Miller, F. Schauer, S. W. Van Sciver, "Comparative Analysis of Design Options for Current Leads for Wendelstein 7-X Magnet System," IEEE Trans. o. Appl. Supercond., Vol. 12 (2002), pp. 1301 - 1304.

[3] W.H. Fietz, R. Heller, A. Kienzler, and R. Lietzow, "High Temperature Superconductor Current Leads for WENDELSTEIN 7-X and JT-60SA," IEEE Trans. on Appl. Supercond. vol 19, no 3 (2009), pp. 2202-2205.

[4] R. Heller, S. Drotziger, W.H. Fietz, S. Fink, M. Heiduk, A. Kienzler, C. Lange, R. Lietzow, T. Möhring, P. Rohr, T. Rummel, T. Mönnich, and K.-P. Buscher, "Test Results of the High Temperature Superconductor Prototype Current Leads for Wendelstein 7-X," IEEE Transactions on Applied Superconductivity,“Vol. 21, No. 3, June 2011, pp. 1062-1065.

[5] R. Heller, W.H. Fietz, P. Keller, B. Ringsdorf, et al, "Electrical, mechanical and thermal characterisation of Bi-2223/AgAu material for use in HTS current leads for W7-X", IEEE Trans. on Appl. Supercond., vol 18, no 2 (2008), pp. 1443-1446.

[6] R. Lietzow, R. Heller; H. Neumann, "Performance of heat exchanger models in upside-down orientation for the use in HTS current leads for W7-X", Advances in Cryogenic Engineering: Vol. 53 (2008), pp. 1243-1250.

[7] C. P. Dhard, Th. Rummel, D. Zacharias, V. Bykov,Th. Moennich, K.-P. Buscher, "Thermo-mechanical tests on W7-X current lead flanges," Fusion Engineering and Design, 2013, http://dx.doi.org/10.1016/j.fusengdes.2013.02.160.

[8] S. Drotziger, K.-P. Buscher, W. H. Fietz, M. Heiduk, R. Heller, M. Hollik, C. Lange, R. Lietzow, Th. Moennich, Th. Richter, Th. Rummel, "Overview of results from Wendelstein7-X HTS current lead testing," Fusion Engineering and Design. (2013), http://dx.doi.org/10.1016/j.fusengdes.2013.01.104.

[9] A. Lumsdaine, T. Brown, M. Cole, P. Fogarty, J. Harris, P. Heitzenroeder, K. Logan, G. McGinnis, H. Neilson, T. Rummel, and L. Wegener, "United States Contributions to Wendelstein 7-X," IEEE Transactions on Plasma Science, vol. 64 (2013), no. 3, in press. 